Revista Brasil. Bot., V.34, n.3, p.447-461, jul.-set. 2011

\title{
A subtribo Cranichidinae Lindl. (Orchidaceae) no Estado do Paraná, Brasil
}

\author{
TOMAS ANDRÉ MACAGNAN ${ }^{1}$, ERIC DE CAMARGO SMIDT ${ }^{1,3} \mathrm{e}$ \\ CECÍLIA OLIVEIRA DE AZEVEDO²
}

(recebido: 10 de dezembro de 2010; aceito: 18 de agosto de 2011)

\begin{abstract}
The subtribe Cranichidinae Lindl. (Orchidaceae) in the Paraná State, Brazil). The aim of this study was to describe the species of the subtribe Cranichidinae occurring in the Paraná State, due to the few information available about its flora. Eight species of Cranichidinae, originally collected in 38 localities, were found through the analysis of herbarium specimens. Cranichidinae are terrestrial herbs, with sessile to petiolate leaves, racemose inflorescence and non-resupinate flowers, usually green or white. Baskervilla Lindl. is represented only by B. paranaensis (Kraenzl.) Schltr.. Cranichis Sw. is characterized by a cochlear white and green spotted lip, and the genus is represented by C. muscosa Sw. and C. candida (Barb. Rodr.) Cogn.. Prescottia was the most diverse genus with five species, P. densiflora (Brongn.) Lindl., P. lancifolia Lindl., P. oligantha (Sw.) Lindl., P. montana Barb. Rodr. and P. stachyodes (Sw.) Lindl., and is recognized by a hooded lip with involute margins. Cranichidinae occurs mainly in Estepe Ombrófila and Floresta Ombrófila Densa. Baskervilla paranaensis, C. muscosa, P. lancifolia and P. montana are endangered species in Paraná. The lectotype of Cranichis candida, Prescottia epiphyta Barb. Rodr., P. microrhiza Barb. Rodr., P. pubescens Barb. Rodr. and P. nivalis Barb. Rodr. were designated herein. Prescottia epiphyta is a new synonym for $P$. lancifolia, and $P$. microrhiza and $P$. nivalis are new synonyms for $P$. oligantha.
\end{abstract}

Key-words - Baskervilla, Cranichis, Flora of Paraná, IUCN, Prescottia

RESUMO - (A subtribo Cranichidinae Lindl. (Orchidaceae) no Estado do Paraná, Brasil). O objetivo deste estudo foi descrever as espécies da subtribo Cranichidinae ocorrentes no Paraná, devido a pouca informação disponível sobre sua flora. Oito espécies de Cranichidinae coletadas em 38 localidades foram encontradas a partir de análises de espécimes de herbários. Cranichidinae são ervas terrestres, com folhas sésseis a pecioladas, inflorescência racemosa e flores não ressupinadas, normalmente verdes ou brancas. Baskervilla Lindl., representada apenas por B. paranaensis (Kraenzl.) Schltr., possui labelo saciforme projetado para trás em bolsa arredondada e pétalas unguiculadas. Cranichis Sw. possui labelo cocleado, branco com manchas verdes, e o gênero é representado por C. muscosa Sw. e C. candida (Barb.Rodr.) Cogn.. Prescottia é o gênero mais diverso, com cinco espécies, P. densiflora (Brongn.) Lindl., P. lancifolia Lindl., P. oligantha (Sw.) Lindl., P. montana Barb. Rodr. e P. stachyodes (Sw.) Lindl., e pode ser reconhecido por possuir labelo calceolado com margens involutas. Cranichidinae ocorrem principalmente em Estepe Ombrófila e Floresta Ombrófila Densa. Baskervilla paranaensis, C. muscosa, P. lancifolia e P. montana são consideradas espécies ameaçadas no Paraná. Cranichis candida, Prescottia epiphyta Barb. Rodr., P. microrhiza Barb. Rodr., P. pubescens Barb. Rodr. e P. nivalis Barb. Rodr. tiveram seus lectótipos determinados. Prescottia epiphyta é considerada como sinônimo novo de P. lancifolia e P. microrhiza e P. nivalis sinônimos de $P$. oligantha.

Palavras-chave - Baskervilla, Cranichis, Flora do Paraná, IUCN, Prescottia

\section{Introdução}

Orchidaceae é uma família de monocotiledôneas pertencente à ordem Asparagales (APG III 2009). Plantas de grande importância comercial, as orquídeas são vastamente cultivadas. Existem pelo menos 24.000 espécies de orquídeas, o que torna a família Orchidaceae a maior em número de espécies entre as angiospermas

1. Universidade Federal do Paraná, Centro Politécnico, Setor de Ciências Biológicas, Departamento de Botânica, Av. Cel. Francisco H. dos Santos, s.n., Jardim das Américas, 80530-900 Curitiba, PR, Brasil.

2. Universidade Estadual do Sudoeste da Bahia, Departamento de Ciências Naturais, Estrada do Bem-Querer, km 4, s.n., Bairro Universitário, 45083-900 Vitória da Conquista, BA, Brasil.

3. Autor para correspondência: ecsmidt@yahoo.com.br
(Raven et al. 2007). São amplamente distribuídas, mas a maior diversidade de orquídeas e a maioria das espécies epífitas ocorrem nos trópicos, especialmente em montanhas (Dressler 1993). No Brasil há 235 gêneros de orquídeas e 2419 espécies (Barros et al. 2010).

Orchidaceae abrange cinco subfamílias, dentre elas Orchidoideae, que compreende sete tribos. A tribo Cranichideae compreende 93 gêneros e cerca de 600 espécies, em sua maioria terrestres, e vastamente distribuídas pelos trópicos e subtrópicos, com espécies em regiões temperadas da Austrália, da Ásia e das Américas do Norte e do Sul (Pridgeon et al. 2003). Dressler (1993) reconheceu seis subtribos em Cranichideae, dentre elas Cranichidinae e Prescottiinae, restritas ao neotrópico. Dressler (1993) separou Prescottiinae de Cranichidinae devido à presença de rostelo laminar em Prescottiinae e 
rostelo terminando em ponta aguda em Cranichidinae. Prescottiinae possui 99 espécies em sete gêneros e Cranichidinae 152 espécies em nove gêneros. Pridgeon et al. (2003) incluíram Prescottiinae dentro de Cranichidinae, baseando-se em padrões filogenéticos. Dados moleculares indicam que esse grupo com flores não-ressupinadas é monofilético e que Prescottiinae seria parafilético se fosse separado de Cranichidinae (Salazar et al. 2003).

Cranichidinae são descritas como ervas terrestres, litófitas ou raramente epífitas, com rizoma condensado, raramente alongado, às vezes ausente. Possuem uma a várias folhas, agrupadas em roseta basal ou em espiral, não-articuladas e frequentemente pecioladas. A inflorescência geralmente é terminal, ereta e racemosa, e as brácteas do escapo são folhosas. As flores são pequenas a médias, não-ressupinadas e frequentemente pilosas. As sépalas são subsimilares, sendo que as laterais são mais ou menos conatas. As pétalas são menores que as sépalas, às vezes adnatas à sépala dorsal. O labelo normalmente é saquiforme, às vezes unido à coluna na parte basal, podendo apresentar esporão. A coluna é curta a alongada, reta ou curva. A antera é dorsal e ereta, e possuem duas ou quatro polínias e dois a quatro caudículos. O viscídio é terminal e geralmente pequeno. O estigma não é dividido (Pridgeon et al. 2003).

O Estado do Paraná apresenta cerca de 7000 espécies de plantas, das quais cerca de 330 foram tratadas em monografias para o estado, o que mostra a carência de informações disponíveis sobre a sua flora. Entre as monocotiledôneas, a família Orchidaceae é a mais diversa no estado, com 123 gêneros e 594 espécies nativas (Barros et al. 2010). Atualmente, com estudos filogenéticos publicados em diversos níveis taxonômicos, há uma mudança muito grande na circunscrição de gêneros, o que torna a necessidade de revisão de floras urgente, com grande impacto em estratégias de conservação.

A partir de estudos sobre a flora de Orchidaceae verificou-se que Cogniaux (1893-1896) não encontrou Cranichidinae no Estado do Paraná. Hoehne (1945) encontrou cinco espécies para o estado: uma de Baskervilla Lindl, B. paranaensis (Kraenzl.) Schltr.; uma de Cranichis Sw., C. candida (Barb.Rodr.) Cogn.; e três espécies de Prescottia Lindl., P. densiflora (Brongn.) Lindl., P. micrantha Lindl. e P. epiphyta Barb.Rodr. Mais recentemente, Pabst \& Dungs (1975) citaram 11 espécies de Cranichidinae para o Paraná: B. paranaensis, C. candida, P. stachyodes (Sw.) Lindl., P. montana Barb. Rodr., P. nivalis Barb.Rodr., P. plantaginifolia Lindl. ex Hook. (citada como P. plantaginea Lindl.), P. densiflora, P. microrhiza Barb.Rodr., P. oligantha (Sw.) Lindl., P. epiphyta e P. lancifolia Lindl.
Baskervilla é caracterizado pela presença de calos no labelo formando uma entrada tubular para o esporão e pétalas oblíquas, mas não bipartidas. Cranichis é caracterizado pela coluna alada, labelo não lobado, base côncava e ovário pubescente. Prescottia possui labelo calceolado, com margens involutas, sem constrição na porção superior (Pridgeon et al. 2003).

Este trabalho apresenta descrições e ilustrações para todas as espécies de Cranichidinae do Paraná, além de dados sobre a distribuição geográfica, habitats e estado de conservação de cada táxon. Apresenta ainda chaves de identificação para os gêneros e espécies estudadas.

\section{Material e métodos}

Análises morfológicas foram feitas com exsicatas obtidas a partir dos Herbários paranaenses EFC, FUEL, HUCP, HUPG, MBM, UPCB e do Herbário do Instituto de Botânica de São Paulo (SP), além de consulta a herbários estrangeiros com exsicatas disponíveis na internet (BM, K, MO, NY, S) (acrônimos segundo Holmgren et al. 1990) e complementadas com materiais coletados em campo. A terminologia morfológica adotada foi baseada em Gonçalves \& Lorenzi (2007), Harris \& Harris (1994) e Stern (2004). A abreviação dos autores de cada táxon está de acordo com Brummitt \& Powel (1992). Os sinônimos aceitos neste trabalho estão de acordo com Azevedo (2009) e Govaerts (2010). As exsicatas foram analisadas em laboratório, sendo que as medidas foram realizadas com auxílio de paquímetro ou microscópio estereoscópico com escala acoplada. A distribuição geográfica dos táxons no Estado do Paraná foi plotada sobre mapa delimitado por quadrículas de $1^{\circ} \times 1^{\circ}$ através do programa DIVA-GIS (Hijmans et al. 2005). O estado de conservação de cada táxon foi inferido seguindo as recomendações do sistema IUCN (2008).

A descrição dos habitats ocupados pelas espécies foi baseada nas cinco regiões ou zonas de paisagens naturais reconhecidas para o estado (Maack 1968): Litoral, Serra do Mar, Primeiro, Segundo e Terceiro Planaltos. Nestas são encontrados cinco tipos de vegetação (Veloso et al. 1991): 1. Floresta Ombrófila Densa, no litoral e Serra do Mar, com os subtipos de floresta Altomontana (acima de $1.000 \mathrm{~m}$ ), Montana (400-1.000 m), Submontana (30-400 m) e de Terras Baixas (até $30 \mathrm{~m}$ ), além de formações associadas (refúgios ou campos de altitude; formações pioneiras ou restinga e mangue); 2. Floresta Ombrófila Mista, nas regiões mais altas ao sul da região planaltina; 3. Estepe Ombrófila (Campos Gerais) nas mesmas regiões; 4. Floresta Estacional Semidecidual Subxérica (norte e oeste do Segundo e Terceiro Planaltos); 5. Savana Estacional Subxérica (Cerrado), no nordeste do estado.

\section{Resultados e discussão}

Subtribo Cranichidinae Lindl., Gen. Spec. Orch. Pl., 441. 1840. Tipo: Cranichis Sw., Prodr., 120. 1788. 
Prescottiinae Dressler, Lindleyana, 5: 115. 1990. Tipo: Prescottia Lindl., Exot. Fl., 2: t. 115. 1824.

Ervas terrestres, raro epífitas, com raízes carnosas e fasciculadas, pilosas ou vilosas. Rizoma condensado, raramente alongado, às vezes ausente. Folhas uma a várias; se várias, em roseta basal, convolutas, conduplicadas ou subplicadas, não-articuladas, relativamente delgadas a levemente carnosas, frequentemente pecioladas. Inflorescência terminal, ereta, pendente, racemosa, multiflora; brácteas folhosas. Flores pequenas a médias, não-ressupinadas, frequentemente pilosas. Sépalas subsimilares, as laterais às vezes mais ou menos conatas. Pétalas delgadas, menores que as sépalas, às vezes adnatas à sépala dorsal. Labelo normalmente saciforme, às vezes unido à coluna na parte basal, podendo apresentar esporão. Coluna curta a alongada, reta ou curva; antera dorsal, ereta, sub-igual ao rostelo; polínias duas ou quatro; caudículos dois ou quatro, viscídio terminal, estigma não dividido.

Foram encontradas oito espécies de Cranichidinae, coletadas em 38 municípios do Paraná: Baskervilla paranaensis, Cranichis candida, C. muscosa, Prescottia densiflora, $P$. lancifolia, $P$. montana, $P$. oligantha e $P$. stachyodes. As espécies de Cranichidinae ocorrem principalmente na Floresta Ombrófila Densa e na Estepe Ombrófila.

Chave para identificação dos gêneros de Cranichidinae encontrados no Paraná:

1. Flores sésseis; labelo calceolado 3. Prescottia

1. Flores pediceladas; labelo de outro tipo

2. Labelo saquiforme; pétalas unidas à base da coluna 1. Baskervilla

2. Labelo coclear; pétalas livres até a base da coluna 2. Cranichis

1. Baskervilla Lindl., Gen. Sp. Orchid. Pl., 505. 1840. Tipo: Baskervilla assurgens Lindl., Gen. Sp. Orchid. Pl., 505. 1840.

Ervas terrestres. Folhas ovais a lanceoladas, pecioladas. Inflorescência terminal, ereta, alongada; escapo laxamente embainhado; brácteas glabras. Flores pediceladas, brancas a esverdeadas. Sépalas livres. Pétalas com unguículo adnato à coluna e uma lâmina livre. Labelo carnoso, adnato à coluna na base ou próximo dela, saciforme, profundamente côncavo ou com esporão curto, com um par de calos na base formando uma entrada tubular para o esporão. Coluna claviforme, alongada, ereta, sem pé; estigma terminal, oval, horizontal; antera oblongo-ovóide; polínias quatro, oblongo-ovóides.

Gênero de seis espécies nativas da Nicarágua, Costa Rica, Panamá e Andes, com uma espécie no Brasil (Pridgeon et al. 2003).

1.1. Baskervilla paranaensis (Kraenzl.) Schltr., Repert. Spec. Nov. Regni Veg., 16: 320. 1920. 三 Ponthieva paranaensis Kraenzl., Kongl. Svenska Vetensk. Acad. Handl., 46(10): 43. 1911. Tipo: BRASIL: PARANÁ, Jaguariaíva, P.K.H. Dusén 10084 (S, NY).

Figura $1 \mathrm{~A}-\mathrm{G}$

Erva terrestre. Folhas 2-6, basais, pecioladas; pecíolo 5,5-23,5 cm compr., verde; lâmina 6-11,5 × 2-5 cm, oval a lanceolada, ápice agudo, base atenuada, membranácea, verde, margem inteira. Inflorescência laxa, $c a$. 60 flores; escapo $28 \mathrm{~cm}$ compr., $3 \mathrm{~mm}$ espessura, verde; brácteas do escapo ca. 3, 12-20 × 4-6 mm, lanceoladas, verdes, ápice agudo; raque $c a$. 15,5 cm compr. Brácteas das flores 5-10 × 1-2 mm, lanceoladas, verdes, ápice agudo. Flor ereta, branca e verde; pedicelo 6-8,5 mm compr.; sépala dorsal 8-8,4 × 2-2,7 mm, membranácea, oblonga, verde, ápice obtuso; sépalas laterais 8,9-9 × 4,6-5,2 mm, membranáceas, assimétricas, com lado exterior salientado e arredondado na base, semi-oval, verdes; pétalas unguiculadas, 8-8,3 × 1,8 mm, membranáceas, unguículo 2,5 mm compr., este linear e concrescido com a face dorsal da coluna, lâmina oblonga, verde-esbranquiçada, ápice obtuso; labelo 7,8-8 $\times 3$-3,9 mm, saquiforme, projetado para trás em bolsa arredondada semimembranácea e com base carnosa, com duas projeções marginais em forma de asa, 2-2,2 mm compr., branco; coluna 6,8-7,5 mm compr., com a parte superior mais espessada; antera dorsal na extremidade da coluna.

Distribuição geográfica e habitat(figura 2): Baskervilla paranaensis foi coletada em quatro municípios do Paraná, ocorrendo na Estepe Ombrófila e na Floresta Ombrófila Densa (Montana e Terras Baixas). Fora do Estado do Paraná é encontrada nos Estados do Rio de Janeiro, São Paulo e Santa Catarina (Barros et al. 2011).

Estado de conservação: Baskervilla paranaensis deve ser enquadrada na categoria vulnerável (VU) segundo os critérios da IUCN (2008), pois a área de ocupação é restrita, ocorrendo em menos de cinco localidades no Paraná (D2).

Observações: Baskervilla paranaensis é uma espécie rara, porém facilmente caracterizada pelo labelo projetado para trás em bolsa arredondada, com duas projeções marginais em forma de asa, além das pétalas 

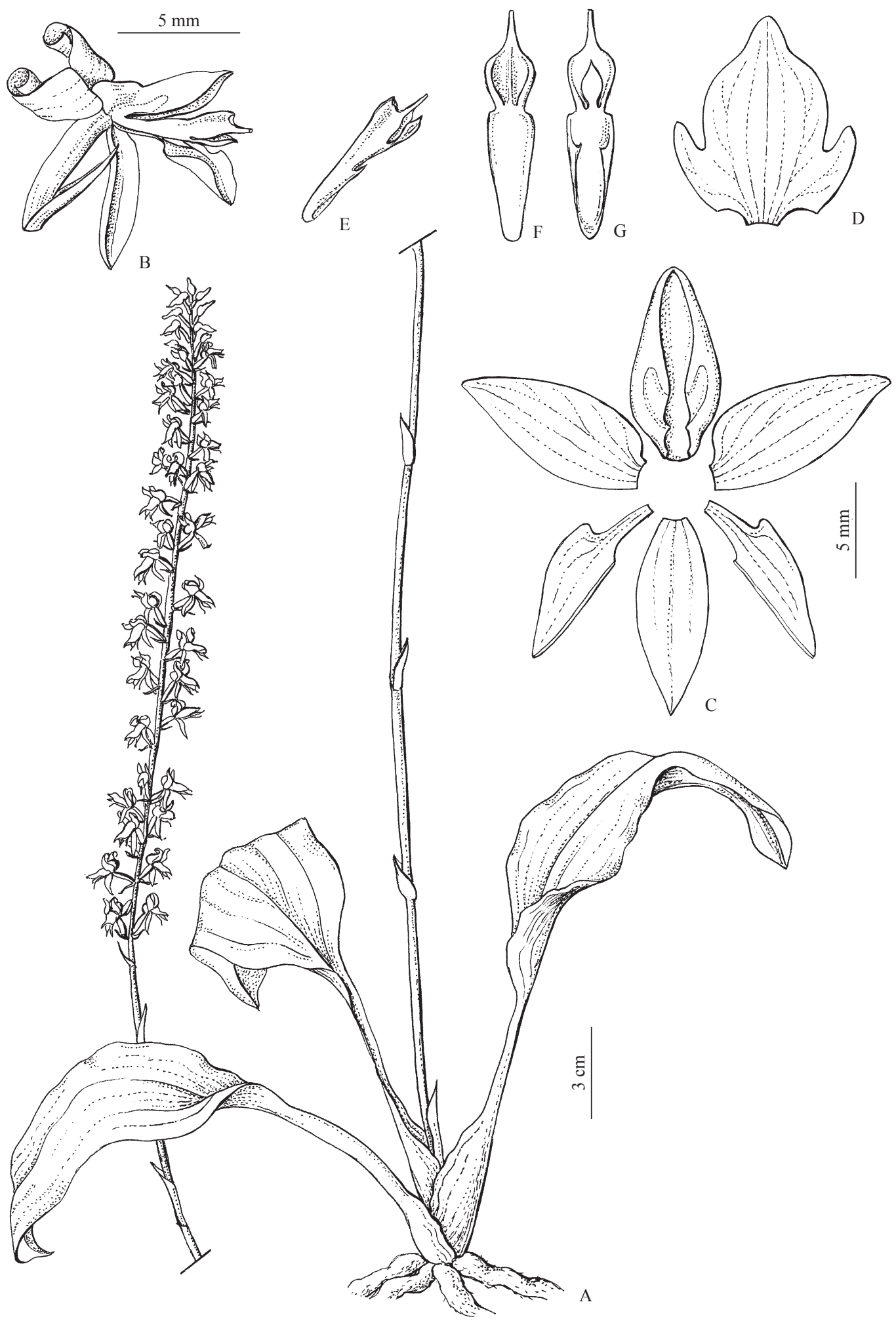

Figura 1. Baskervilla paranaensis. A. Hábito. B. Flor, vista lateral. C. Partes do perianto, sentido horário a partir do topo: labelo, sépala lateral, pétala, sépala dorsal. D. Labelo distendido. E-G. Coluna. E. Vista lateral. F. Vista ventral. G. Vista dorsal. (Blum 18).

Figure 1. Baskervilla paranaensis. A. Habit. B. Flower, lateral view. C. Parts of the perianth, clockwise from top: lip, lateral sepal, petal, dorsal sepal. D. Lip extended. E-G. Column. E. Side view. F. Ventral view. G. Dorsal view. (Blum 18). 
unguiculadas e unidas à base da coluna. Floresce entre fevereiro e setembro.

Material examinado: BRASIL: PARANÁ: Antonina, usina hidrelétrica Parigot de Souza, 06-IX-2006, J.M. Silva 5010 (MBM); Jaguariaíva, s.d., P.K.H. Dusén s.n. (MO 2480080); Jaguariaíva, 5-V-1910, P.K.H. Dusén 10084 (MO, NY); Jaguariaíva, 06-VII-1910, P.K.H. Dusén 10070 (NY); Jaguariaíva, 1-V-1911, P.K.H. Dusén s.n. (NY 533732); Morretes, Serra da Prata, encosta norte da Torre da Prata, 5-II-2010, C.T. Blum \& B. Blum 18 (UPCB); Sengés, Vale do Corisco, 4-V-2006, E. Barbosa 1342 (MBM).

Material adicional examinado: BRASIL: São PAULO: São Miguel Arcanjo, Parque Estadual de Carlos Botelho, 23-IV-2002, A.P. Savassi et al. 318 (MBM).

2. Cranichis Sw., Prodr., 120. 1788.

Tipo: Cranichis muscosa Sw., Prodr., 120. 1788.

Ervas terrestres, cespitosas. Folhas uma a várias, base em roseta, membranáceas, ovais a lanceoladas, pecioladas. Inflorescência terminal, ereta, alongada; escapo e raque puberulentos; brácteas folhosas. Flores pediceladas, brancas, podendo apresentar manchas verdes. Sépalas livres. Pétalas livres, bem mais estreitas que as sépalas, às vezes com margens ciliadas. Labelo coclear, com nervuras reticuladas verdes ou distintamente marcadas, séssil com a margem recurvada para cima, raramente unguiculado. Coluna carnosa, curta, ereta, sem pé; estigma terminal, oval a elíptico, rodeado por uma aba, horizontal; antera oblonga a oval; polínias quatro, ovóide-claviformes.

Gênero de 30 espécies distribuídas do México e do Sul do Caribe até a Bolívia e a Argentina (Pridgeon et al. 2003), sendo cinco nativas do Brasil (Barros et al. 2010).

Cogniaux (1893-1896) não citou espécies de Cranichis para o Paraná. Tanto Hoehne (1945) como Pabst \& Dungs (1975) descreveram apenas C. candida para o estado, mas há outra espécie que ocorre no Paraná: Cranichis muscosa Sw.

Chave para identificação das espécies de Cranichis encontradas no Paraná:

1. Inflorescência laxa; brácteas do escapo lanceoladas; pétalas com margens glabras 2.1. C. candida

1. Inflorescência congesta; brácteas do escapo ovais a elípticas; pétalas com margens pilosas .... 2.2. C. muscosa

2.1. Cranichis candida (Barb.Rodr.) Cogn., Fl. Bras. 3(4): 248. 1895. E Cystochilum candidum Barb. Rodr., Gen. Sp. Orchid. 1: 198. 1877. Protólogo: “Croissant sur l'humus dans les lieux humides, à lómbre dês capões, près du Pico do Frade à Caldas, et dans plusieurs autres endriots à l'ombre dês capoeiras de la Comarca do Sapucahy, Minas Gerais. Floraison au móis de Mars". Lectótipo (aqui designado): desenho original de Barbosa Rodrigues (t. 82) depositado na biblioteca do Jardim Botânico do Rio de Janeiro [reproduzido em "Iconographie des Orchidées du Brésil", Sprunger et al. (1996), 2: t. 139].

Figura 3A-D

Erva terrestre. Folhas 2-5, basais, pecioladas; pecíolo 1,9-3,6 cm compr., verde; lâmina 2,1-5,5 × 1,2-3,1 cm, membranácea, elíptica a oval, ápice agudo, base atenuada a obtusa, glabra, verde, margem inteira. Inflorescência laxa, 20-40 flores; escapo 20-29 cm compr., 1,9-2,5 mm espessura, verde; brácteas do escapo 3-4, 17,5-22,7 × 1,3$5 \mathrm{~mm}$, lanceoladas, verdes, ápice agudo a acuminado; raque 4,9-10,5 cm compr., 1,9-2,5 mm espessura, verde. Brácteas das flores 2,5-4,1 × 0,7-0,9 mm, lanceoladas, verdes, ápice acuminado, glabras. Flor ereta, branca; pedicelo 5-6 mm compr.; sépala dorsal 1,7-2,1 × 0,9-
1,4 mm, membranácea, oval, branca, ápice obtuso; sépalas laterais 2-2,5 × 1,1-1,5 mm, membranáceas, ovais, brancas, ápice agudo; pétalas 1,4-1,7 ×0,5$0,6 \mathrm{~mm}$, membranáceas, oblongas, brancas, ápice obtuso; labelo 2-2,1 × 1,1-1,3 mm, levemente unguiculado, coclear, submembranoso, branco com nervuras verdes espessadas; coluna alada, 1,2-1,3 mm compr.

Distribuição geográfica e habitat (figura 2): Cranichis candida foi coletada em 16 municípios do Estado do Paraná, ocorrendo na Estepe Ombrófila, na Floresta Ombrófila Densa (Montana, Altomontana e Terras Baixas) e na Floresta Ombrófila Mista. Fora do Estado do Paraná é encontrada nos Estados de Santa Catarina, Rio Grande do Sul, Minas Gerais, São Paulo, Rio de Janeiro e no Distrito Federal (Barros et al. 2011).

Estado de conservação: Segundo os critérios da IUCN (2008), Cranichis candida não se enquadra como uma espécie ameaçada, devendo ser considerada na categoria pouco preocupante (LC).

Observações: Mais comum que Cranichis muscosa, C. candida diferencia-se por possuir inflorescência laxa, brácteas do escapo lanceoladas e pétalas com margem glabra, além da reticulação das folhas ser mais evidente. Geralmente floresce entre março e junho. 


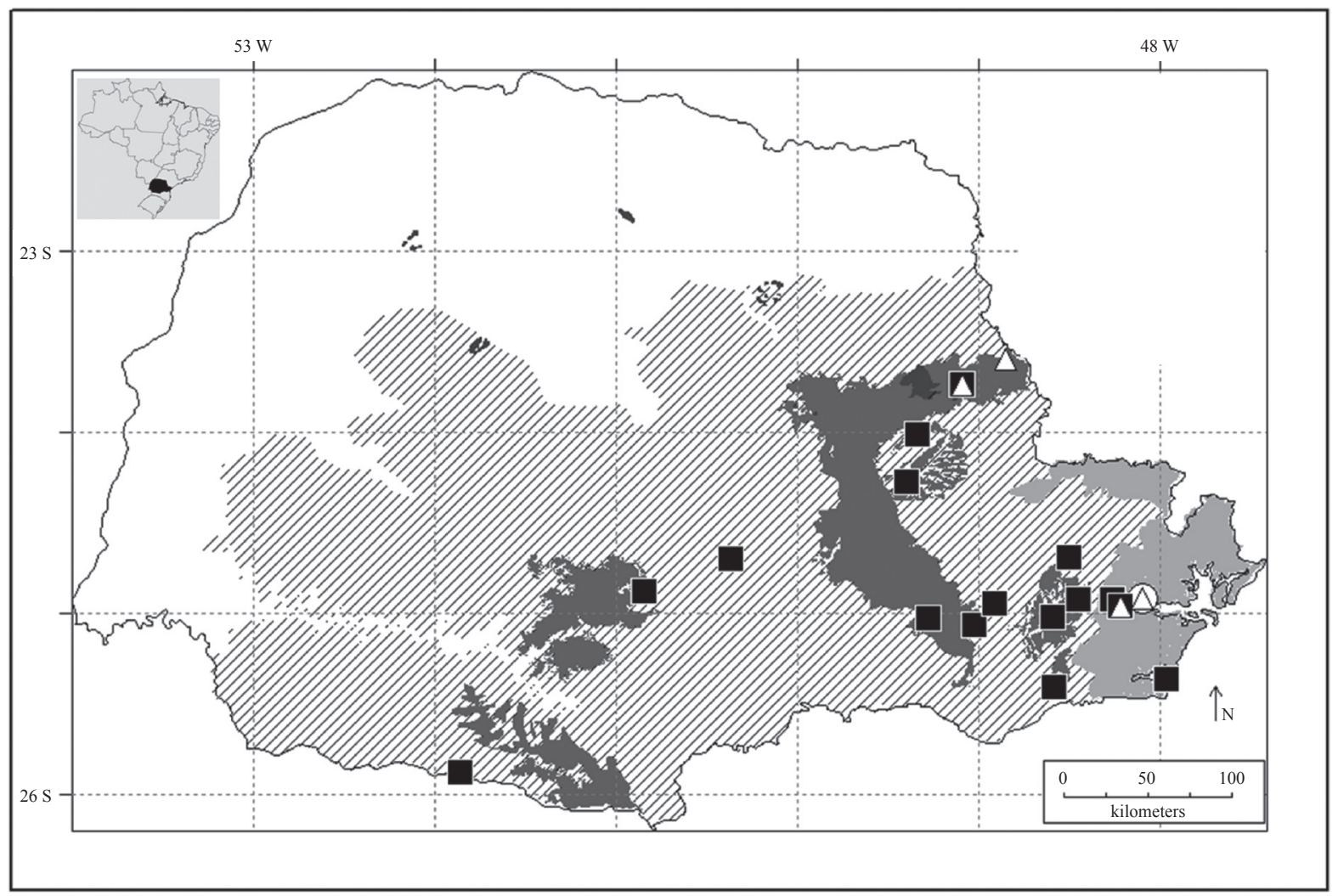

Figura 2. Mapa da distribuição geográfica de Baskervilla paranaensis, Cranichis candida e C. muscosa no Estado de Paraná ( $\square=$ estepe ombrófila; $\square$ = floresta estacional semidecidual subxérica; $\square=$ floresta ombrófila densa; $叉$ = floresta ombrófila mista; $\square=$ savana estacional subxérica; $\boldsymbol{\square}=$ Cranichis candida; $\Delta=$ Baskervilla paranaensis $; \mathrm{O}=$ Cranichis mucosa .

Figure 2. Map of geographic distribution of Baskervilla paranaensis, Cranichis candida and C. muscosa in the Parana State ( $\square=$ ombrophilous steppe; $\square=$ subxeric seasonal semidecidous forest; $\square=$ dense ombrophilous forest; $\square=$ mixed ombrophilous forest; $\square=$ subxeric seasonal savanna; $=$ Cranichis candida; $\Delta=$ Baskervilla paranaensis $; \mathrm{O}=$ Cranichis mucosa $)$.

Material examinado: BRASIL: PARANÁ: Balsa Nova, São Luis do Purunã, 1-VI-1981, G. Hatschbach 43918 (MBM); Bocaiúva do Sul, Bocaina, 20-IV-1998, J.M. Silva et al. 2340 (MBM); Castro, Rio Pitangui, 14IV-1966, G. Hatschbach 14214 (MBM); Clevelândia, Cia. Brandalize, 20 km N., 3-V-1966, J.C. Lindeman \& J.H. Haas 1183 (MBM); Guarapuava, Rio São Jerônimo, 25-III-2003, C. Kozera s.n. (EFC 9767); Guaratuba, Serra de Araçatuba, Morro dos Perdidos, 23-IV-1999, E.P. Santos et al. 778 (UPCB, SP); Jaguariaíva, 26V-1910, P. Dusén s.n. (MO 2816445); Morretes, 1IV-1910, P.K.H. Dusén s.n. (NY 414870); Morretes, Estrada da Graciosa, Curva Ferradura, 6-VIII-1983, G. Hatschbach 47624 (MBM); Piraí do Sul, Serra das Furnas, 30-XI-1957, G. Hatschbach 3925 (MBM); Piraquara, Fazenda Experimental Agronomia, G. Gaiola, 24-III-1970, N. Imaguire 2308 (MBM); Porto Amazonas, Rio Iguaçu, 12-VI-2001, O.S. Ribas et al. 3607 (MBM); Porto de Cima, 10-IV-1910, P. Dusén 9838 (MO); Prudentópolis, Relógio, 14-IV-1964, G.
Hatschbach s.n. (MBM 49129); São José dos Pinhais, Guaricana, 24-III-1986, J.M. Silva \& A. Carvalho 105 (MBM); São Luiz do Purunã, 1-V-1948, G. Hatschbach 969 (MBM, SP); Tijucas do Sul, Saltinho, 7-IV-1971, G. Hatschbach 26612 (MBM).

2.2. Cranichis muscosa Sw., Prodr., 120. 1788. Tipo: JAMAICA: sem local, Swartz s.n. (S).

= Cranichis bradei Schltr., Anexos Mem. Inst. Butantan, Secc. Bot. 1(4): 32. 1922. Tipo: BRASIL: São PAUlo, Morro das Pedras, Iguape, A.C. Brade 8116 (K).

Figura 3E-H

Erva terrestre. Folhas $c a$. 4, basais, pecioladas; pecíolo 3,5-5,5 cm compr., verde; lâmina 4,5-7 × 3$3,7 \mathrm{~cm}$, membranácea, oval a elíptica, ápice agudo, base atenuada, glabra, verde, margem inteira. Inflorescência congesta, 10-15 flores; escapo 13,5-16 cm compr., $2 \mathrm{~mm}$ espessura, marrom-esverdeado; brácteas do escapo ca. 4, 6-25 × 5-15 mm, ovais a elípticas, verdes, 


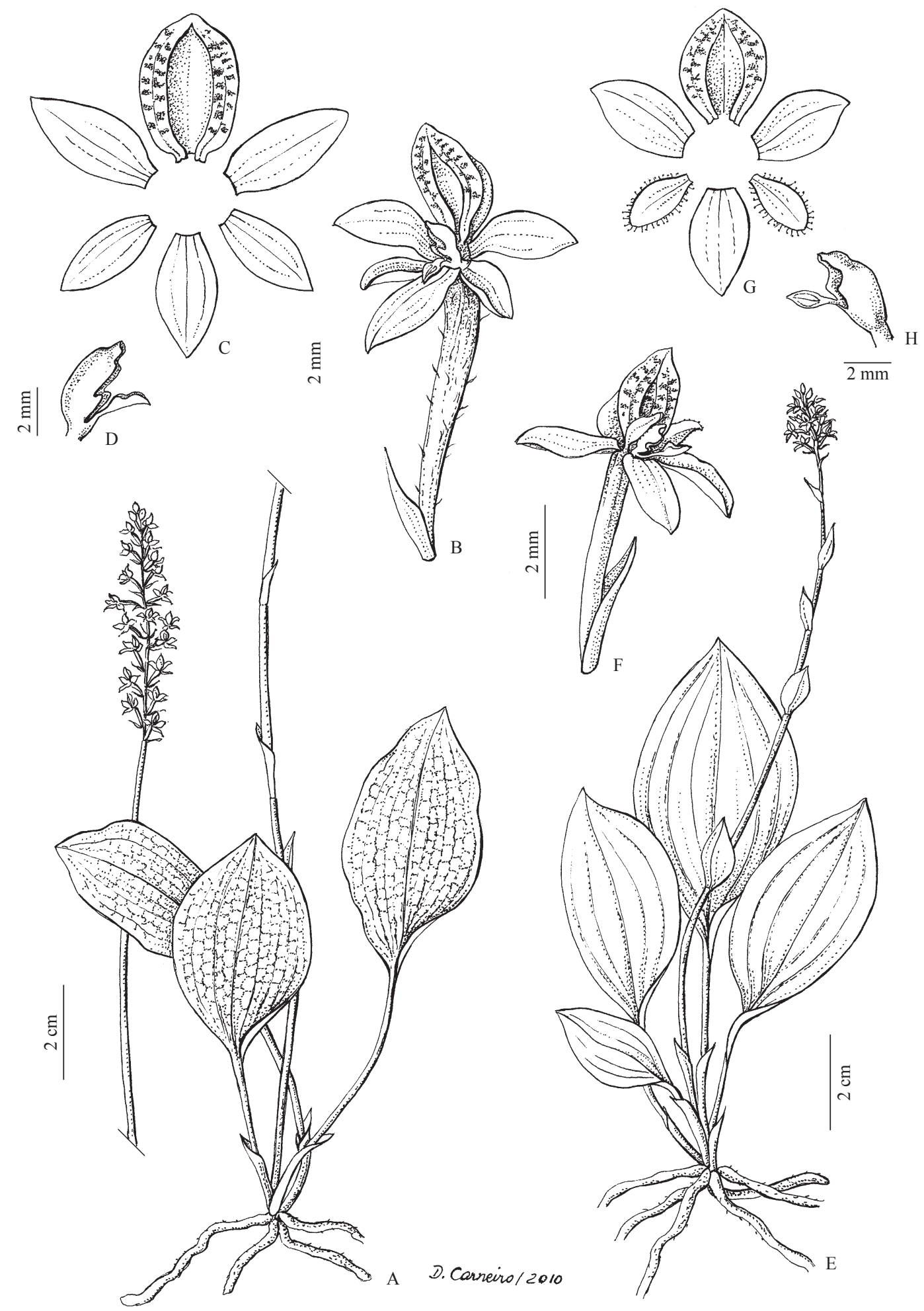

Figura 3. Cranichis candida e C. muscosa. A-D. C. candida (Silva 105). E-H. C. muscosa (Hatschbach 38844). A, E. Hábito. B, F. Flor. C, G. Partes do perianto, sentido horário a partir do topo: labelo, sépala lateral, pétala, sépala dorsal. D, H. Coluna, vista lateral.

Figure 3. Cranichis candida and C. muscosa. A-D. C. candida (Singh 105). E-H. C. muscosa (Hatschbach 38,844). A, E. Habit. B, F. Flower. C, G. Parts of the perianth, clockwise from top: lip, lateral sepal, petal, dorsal sepal. D, H. Column, side view. 
ápice agudo; raque 1-2 cm compr., $2 \mathrm{~mm}$ espessura, verde. Brácteas das flores $5 \times 1,5 \mathrm{~mm}$, lanceoladas, verdes, ápice acuminado. Flor ereta, branca; pedicelo 4-5 mm compr.; sépala dorsal $4 \times 1,2 \mathrm{~mm}$, membranácea, oval, branca, ápice obtuso; sépalas laterais $4 \times 1,2 \mathrm{~mm}$, membranáceas, lanceoladas a ovais, brancas, ápice agudo; pétalas $3 \times 0,8 \mathrm{~mm}$, membranáceas, oblongas, brancas, ápice obtuso, margem ciliada; labelo $4 \times 3 \mathrm{~mm}$, submembranáceo, coclear, branco com nervuras verdes; coluna alada, ca. 1,5 mm compr., glabra.

Distribuição geográfica e habitat (figura 2): Cranichis muscosa foi coletada em apenas um município do Paraná, em Antonina, ocorrendo na Floresta Ombrófila Densa (Terras Baixas). Fora do estado do Paraná, é encontrada nos estados do Amazonas e São Paulo (Barros et al. 2011).

Estado de conservação: Segundo critérios da IUCN (2008), Cranichis muscosa deve ser enquadrada na categoria de espécie em perigo crítico (CR), ocorrendo em apenas uma localidade no estado do Paraná (D1).

Observações: Cranichis muscosa possui manchas no labelo, assim como $C$. candida, porém a nervação das folhas é mais saliente em C. muscosa, assim como a inflorescência é congesta em C. muscosa e laxa em $C$. candida. Floresce em agosto.

Material examinado: BRASIL: PARANÁ: Antonina, Sapitanduva, 18-VIII-1976, G. Hatschbach 38844 (MBM).
3. Prescottia Lindl., Exot. Fl., t. 115. 1824. nom. cons. Tipo: Prescottia plantaginifolia Lindl. ex Hook., Exot. Fl., 2: t. 115. 1824.

Ervas terrestres, raramente epífitas, eretas. Folhas basais, pecíolos embainhados na base, lâmina elíptica a oval. Flores sésseis, verdes, brancas ou amareloesverdeadas. Inflorescência terminal, pendente a ereta, escapo delgado, várias brácteas, embainhadas. Sépalas basalmente conatas, raramente livres, eretas, expandidas ou revolutas. Pétalas estreitas, adnatas às sépalas. Labelo unido à coluna, frequentemente auriculado, calceolado, geralmente circundando a coluna. Coluna curta, ereta, subulada; polínias quatro, levemente achatadas.

Gênero de 15 espécies com distribuição neotropical, desde a Flórida, o Caribe e o México até a Argentina, com 12 espécies nativas do Brasil (Azevedo 2009).

Pabst \& Dungs (1975) descreveram nove espécies de Prescottia para o Paraná: P. stachyodes, P. montana, $P$. nivalis, P. plantaginifolia (citada como P. plantaginea), P. densiflora, P. microrhiza, P. oligantha, P. epiphyta e P. lancifolia. Azevedo (2009) realizou uma revisão taxonômica do gênero Prescottia e reduziu para cinco o número de espécies encontradas no Paraná: P. densiflora, P. lancifolia, P. montana, P. oligantha e P. stachyodes, uma vez que $P$. epiphyta foi considerada sinônimo de $P$. lancifolia, e P. microrhiza e $P$. nivalis foram consideradas sinônimos de $P$. oligantha, sinonimizações formalizadas aqui. Além disso, material de $P$. plantaginifolia não foi encontrado para o Paraná nos herbários visitados.

Chave para identificação das espécies de Prescottia encontradas no Paraná:

1. Folhas sésseis a pseudopecioladas 3.1. P. densiflora

1. Folhas pecioladas

2. Inflorescência pendente 3.2. P. lancifolia

2. Inflorescência ereta

3. Flor branca; superfície interna do labelo pilosa 3.4. P. oligantha

3. Flor verde ou amarela; superfície interna do labelo glabra

4. Flor verde a amarela; uma folha; sépalas laterais adpressas ao labelo 3.3. P. montana

4. Flor verde; uma ou mais folhas; sépalas laterais revolutas 3.5. P. stachyodes

3.1. Prescottia densiflora (Brongn.) Lindl., Ann. Mag. Nat. Hist. 1, 6 (34): 52. 1840. $\equiv$ Decaisnea densiflora Brongn., Voy. Coq. Bot. 192 (1): 39. 1829. Tipo: BRASIL: Santa Catarina, A. Brongniart s.n. (lectótipo KL! selecionado por Azevedo \& van den Berg 2007ª). Figura 4A-C

Erva terrestre. Folhas 1-5, sésseis a pseudopecioladas; pecíolo 1-2 cm compr., verde; lâmina 1,5-8 ×0,7$3,2 \mathrm{~cm}$, membranácea, elíptica a oval, verde, ápice agudo a obtuso, base atenuada a obtusa, margem inteira. Inflorescência congesta, ereta, 30-120 flores; escapo 8$30 \mathrm{~cm}$ compr., 0,2-0,3 cm espessura, cilíndrico, verde; brácteas do escapo 4-12, 4,9-35 × 1-8 mm, ovais, ápice agudo a acuminado; raque $2-18 \mathrm{~cm}$ compr., $0,1-0,2 \mathrm{~cm}$ espessura, verde. Brácteas das flores 1,9-4,8 × 0,7$1,6 \mathrm{~mm}$, lanceoladas, ápice acuminado, verdes. Flor ereta, branca; sépala dorsal revoluta, 1,3-1,8 × 0,7$1,4 \mathrm{~mm}$, submembranácea, triangular, ápice agudo; sépalas laterais expandidas, 1,3-1,8 ×0,7-1,3 mm, 
submembranáceas, ovais, ápice agudo; pétalas revolutas, 0,9-1,2 × 0,3-0,5 mm, submembranáceas, lineares, ápice obtuso a agudo; labelo 1-2 × 0,7-1,4 mm, calceolado, membranáceo, branco, superfície interna pilosa; coluna 0,5-0,8 mm compr., glabra.

Distribuição geográfica e habitat(figura 5): Prescottia densiflora foi coletada em nove municípios do Paraná, com o maior número de coletas de Paranaguá. Ocorre na Estepe Ombrófila e na Floresta Ombrófila Densa (Terras Baixas). Fora do Estado do Paraná é encontrada nos Estados de São Paulo, Rio de Janeiro, Santa Catarina e Rio Grande do Sul (Barros et al. 2011).

Estado de conservação: Segundo os critérios da IUCN (2008), Prescottia densiflora não se enquadra como uma espécie ameaçada, devendo ser enquadrada na categoria pouco preocupante (LC).

Observações: Morfologicamente, Prescottia densiflora é muito similar a $P$. oligantha, porém os extremos morfológicos são bem delimitados. Ambas possuem labelo piloso internamente, mas $P$. densiflora tem folhas sésseis a pseudopecioladas e sua inflorescência é congesta. Floresce entre agosto e novembro.

Material examinado: BRASIL: PARANÁ: Alexandra, 5-X-1985, N.S. Shibro 14 (HUCP); Balsa Nova, Serra do Purunã, IX-2009, E.C. Smidt 925 (UPCB); Balsa Nova, Ponte dos Arcos, 21-X-2006, C. Kozera \& O.P. Kozera 3319 (MBM); Carambeí, 24-X-2008, M.E. Engels 43 (HUPG); Curitiba, Parque Barigüi, 6-XI-1996, C. Kozera \& V.A. de O. Dittrich 319 (UPCB); Guaratuba, Brejatuba, 13-VIII-1950, G. Hatschbach 210 (MBM); Guaratuba, Praia do Mendanha, 24-IX-1967, G. Hatschbach 17205 (MBM); Matinhos, Praia Grande, 22-IX-1996, C. Kozera 357 (UPCB); Matinhos, 15-IX-1985, L.M. Krul 4 (HUCP); Morretes, Graciosa, Mãe Catira, 30-IX1984, S.R. Malkowski 22 (HUCP); Paranaguá, Ilha do Mel, Bela Mar de Dentro, 4-X-1986, S.M. Silva 25651 (MBM); Paranaguá, Ilha do Mel, Morro do Farol, 16VIII-1987, R.M.Britez 1758 (FUEL, HUCP); Paranaguá, Ilha do Mel, Morro do Joaquim, 12-IX-1987, R.M. Britez et al. 1786 (FUEL); Paranaguá, Ilha do Mel, Praia do Farol, 3-VIII-1997, S.M. Silva \& C. Kozera s.n. (UPCB 31347); Paranaguá, Ilha do Mel, trilha dos postes, 1-XI1998, C. Giongo 71 (UPCB); Ponta Grossa, 2-X-2008, M.E. Engels 36 (HUPG).

3.2. Prescottia lancifolia Lindl., Gen. sp. Orchid. Pl., 453. 1840. Tipo: BRASIL: Gardner 681 (lectótipo K-L! designado por Azevedo \& van den Berg 2007ª).

= Prescottia epiphyta Barb.Rodr., Gen.spec. Orchid. 1: 179, t. 462. 1877. Protólogo: "Serra da Pedra Branca et dos Poços. Fleurit au óis de Mars.” Syn. Nov. Lectótipo (aqui designado): desenho original de Barbosa Rodrigues (t. 462) depositado na biblioteca do Jardim Botânico do Rio de Janeiro [reproduzido em "Iconographie ói Orchidées du Brésil", Sprunger et al. (1996), 2: t. 86]. Figura 4F-G

Erva epífita. Folhas 2-5, pecioladas; pecíolo 3$6 \mathrm{~cm}$ compr., lâmina $4-9 \times 1,5-2 \mathrm{~cm}$, membranácea, lanceolada, verde, ápice agudo, base atenuada, margem inteira. Inflorescência laxa, pendente, 11-40 flores; escapo 10-13 cm compr., 0,4-10 mm espessura, cilíndrico, verde; brácteas do escapo 2-3, 1-2,5 ×0,5 mm, ovais a triangulares, verdes, ápice agudo a acuminado; raque 4-6 cm compr., 0,4-0,8 cm espessura, verde. Brácteas das flores 3-6 × 1,2-2,6 mm, ovais a triangulares, verdes, ápice acuminado a agudo. Flor ereta, branca; sépala dorsal revoluta, 2-2,6 × 1-1,5 mm, submembranácea, lanceolada a oval, ápice agudo; sépalas laterais expandidas a revolutas, 2,5-3,6 × 1,5-2 mm, submembranáceas, oblongas a ovais, ápice arredondado a agudo; pétalas revolutas, 1,5-2,6 × 0,5-0,8 mm, submembranáceas, lineares, ápice arredondado a agudo; labelo 2-3,5 × 2,5$3 \mathrm{~mm}$, calceolado, membranáceo, branco, superfície interna pilosa; coluna 0,8-1,2 mm compr., glabra.

Distribuição geográfica e habitat(figura 5): Prescottia lancifolia foi coletada em quatro municípios do Paraná, ocorrendo na Floresta Ombrófila Densa (Terras Baixas). Fora do Estado do Paraná é encontrada nos Estados de Minas Gerais, Espírito Santo, São Paulo, Rio de Janeiro e Santa Catarina (Barros et al. 2011).

Estado de conservação: Prescottia lancifolia deve ser enquadrada na categoria vulnerável (VU) segundo os critérios da IUCN (2008), pois a área de ocupação é restrita, ocorrendo em menos de cinco localidades no Paraná (D2).

Observações: A relação entre o comprimento das folhas e das inflorescências tem sido a razão principal, até agora, para a separação entre Prescottia lancifolia e P. epiphyta, o que causava confusão entre estes táxons. As inflorescências podem ser mais curtas do que as folhas, mas elas geralmente são mais longas. Essa característica parece representar uma variação normal da espécie, observada entre os exemplares de uma mesma população. Floresce entre maio e novembro.

Material examinado: BRASIL: PARANÁ: Antonina, BR 116, São Sebastião, 11-IX-1970, G. Hatschbach 24697 (MBM); Guaratuba, Alto da Serra, 13-X-1957, G. Hatschbach 4116 (MBM); Guaratuba, Itareré, 14IX-1982, R. Kummrow 2003 (MBM); Guaratuba, Rio Itareré, 6-XI-2003, J.M. Silva 3877 (MBM); Morretes, Morro 7, 17-V-1964, G. Hatschbach 11286 (MBM); 


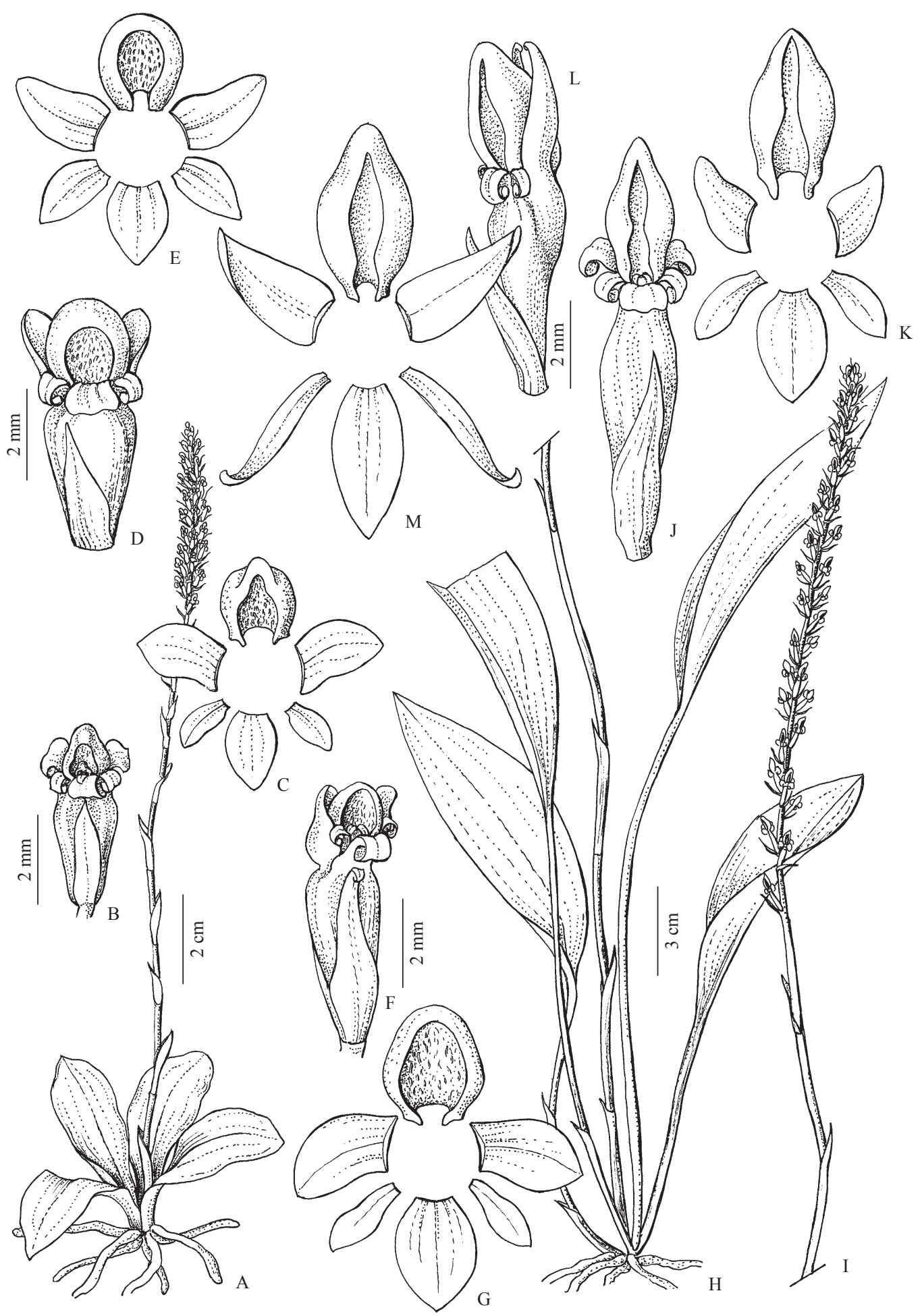

Figura 4. Espécies de Prescottia encontradas no Paraná. A-C. P. densiflora (Smidt 925). D-E. P. oligantha (Guimarães 21039). F-G. P. lancifolia (Blum 52). H-K. P. stachyodes (Santos 893). L-M. P. montana (Dombrowski 2990). A, H. Hábito. B, D, F, J. Flor, vista frontal. L. Flor, vista lateral. C, E, G, K, M. Partes do perianto, sentido horário a partir do topo: labelo, sépala lateral, pétala, sépala dorsal.

Figure 4. Prescottia species found in Parana. A-C. P. densiflora (Schmidt 925). D-E. P. oligantha (Guimarães 21,039). F-G. P. lancifolia (Blum 52). H-K. P. stachyodes (Santos 893). L-M. P. montana (Dombrowski 2990). A, H. Habit. B, D, F, J. Flower, front view. L. Flower, lateral view. C, E, G, K, M. Parts of the perianth, clockwise from top: lip, lateral sepal, petal, dorsal sepal. 
Morretes, Serra do Leão, 10-X-1961, G. Hatschbach 8320 (MBM); Morretes, Morumbi, 1-IX-1991, O.S. Ribas 374 (MBM); Morretes, Serra da Prata, encosta norte da Torre da Prata, 19-X-2008, C.T. Blum \& R.T. Proença 63 (UPCB); Morretes, Serra da Prata, encosta norte da Torre da Prata, 7-V-2009, C.T. Blum \& J. Michelotti 52 (UPCB); Paranaguá, Torre da Prata, 1VII-2003, J.M. Silva 3758 (MBM).

3.3. Prescottia montana Barb.Rodr., Gen. spec. Orchid. 1: 178, t. 485. 1877. Protólogo: "Sur ó sommet de la Pedra Branca, à Caldas. Fleurit au óis d'Avril.” Lectótipo: desenho original de Barbosa Rodrigues (t.485) depositado na biblioteca do Jardim Botânico do Rio de Janeiro (designado por Azevedo \& van den Berg 2007b).

Figura 4L-M

Erva rupícola a terrestre. Folhas uma, basal, peciolada; pecíolo $c a$. $15 \mathrm{~cm}$ compr., verde; lâmina $18 \times 5,1 \mathrm{~cm}$, membranácea, elíptica a lanceolada, ápice agudo, base atenuada, verde, margem inteira. Inflorescência congesta, ereta, ca. 60 flores; escapo ca. $54 \mathrm{~cm}$ compr., $0,4 \mathrm{~cm}$ espessura, cilíndrico, verde; brácteas do escapo $c a$. 5 , 30-60 × 5-10 mm, ovais, verdes, ápice acuminado; raque ca. $12 \mathrm{~cm}$ compr., $4 \mathrm{~mm}$ espessura, verde. Brácteas das flores 6-8 × 1,2-1,9 mm, lanceoladas a ovais, verdes, ápice acuminado. Flor ereta, amarela a verde; sépala dorsal revoluta, 3,3-3,7 × 0,7-0,9 mm, membranácea, oblonga a triangular, verde a amarela, ápice agudo; sépalas laterais adpressas ao labelo, 4,5-4,8 $\mathrm{mm} \times 0,8$ $1 \mathrm{~mm}$, membranáceas, lanceoladas a oblongas, amarelas a verdes, ápice agudo a arredondado; pétalas revolutas, 3,4-3,6 × 0,4-0,6 mm, membranáceas, lineares, amarelas a verdes, ápice obtuso; labelo 4-4,5 × 3-3,3 mm, calceolado, submembranáceo, verde, superfície interna glabra; coluna 1,3-1,4 mm compr., glabra.

Distribuição geográfica e habitat(figura 5): Prescottia montana foi coletada em apenas dois municípios do Paraná, ocorrendo na Estepe Ombrófila. Fora do Estado do Paraná é encontrada nos Estados da Bahia, Goiás, Minas Gerais, Espírito Santo, São Paulo, Rio de Janeiro, Santa Catarina, Rio Grande do Sul e no Distrito Federal (Barros et al. 2011).

Estado de conservação: Prescottia montana deve ser enquadrada na categoria vulnerável (VU) segundo os critérios da IUCN (2008), pois a área de ocupação é restrita, ocorrendo em menos de cinco localidades no Paraná (D2).

Observações: Prescottia montana compartilha muitas similaridades com $P$. stachyodes, como as folhas pecioladas e o labelo internamente glabro, porém $P$. montana possui apenas uma folha e as sépalas laterais são adpressas ao labelo. Floresce em maio.

Material examinado: BRASIL: PARANÁ: Curitiba, Santa Felicidade, 1971, L.T. Dombrowski \& Y.S. Kuniyoshi 3716 (MBM); Palmeira, Col. Quero-Quero, 4-V-1952, G. Hatschbach 2772 (MBM); Palmeira, Col. Quero-Quero, 6-V-1973, G. Hatschbach 31847 (MBM).

3.4. Prescottia oligantha (Sw.) Lindl., Gen. sp. Orchid. P1., 454. 1840. ECranichis oligantha Sw., Prodr., 120. 1788. Tipo: JAMAICA (mont. Caerul.) Swartz s.n. (lectótipo BM! Designado por Azevedo \& van den Berg 2007a).

= Prescottia micrantha Lindl., Bot. Reg. 22: t. 1916. 1836. Tipo: BRASIL: Sierra d'Estrella, Griesebach s.n. (holótipo K-L!).

= Prescottia microrhiza Barb.Rodr., Gen. spec. Orchid. 1: 179, t. 492. 1877. Protólogo: "Suêle bord des chemins pres de la riviere Sapucahy. Fleurit aumois de Mai." syn. nov. Lectótipo (aquêsdo): desenho original de João Barbosa Rodrigues (t. 492) depositado na biblioteca do Jardim Botânico do Rio de Janeiro [reproduzido em "Iconographiêses Orchidées du Brésil", Sprunger et al. (1996), 2: t. 90].

= Prescottia pubescens Barb.Rodr., Gen. spec. Orchid. 1: 178, t. 469. 1877. Protólogo: "Dans lêset de la serra da Pedra Branca à Caldas. Fleurit au móis de Mai." syn. nov. Lectótipo (aqui designado): desenho original de João Barbosa Rodrigues (t. 469) depositado na biblioteca do Jardim Botânico do Rio de Janeiro [reproduzido em "Iconographiêses Orchidées du Brésil”, Sprunger et al. (1996), 2: t.87].

= Prescottia nivalis Barb.Rodr., Gen. spec. Orchid. 2: 278, t. 818. 1881. Protólogo: "Croissanêsmêses fougereêses bordêses chemins pres Palmeiras, à Rio de Janeiro. Fleuriemen Juillet." synon. nov. Lectótipo (aqui designado): desenho original de Barbosa Rodrigues ( $t$. 818) depositado na biblioteca do Jardim Botânico do Rio de Janeiro [reproduzido em "Iconographiêses Orchidées du Brésil", Sprunger et al. (1996), 2: t. 88B.]

Figura 4D-E

Erva terrestre. Folhas 3-4, basais, pecioladas; pecíolo 1-5 cm compr., verde; lâmina 2,3-5 × 0,9-2,2 cm, membranácea, elíptica a lanceolada, ápice agudo, base atenuada a obtusa, verde, margem inteira. Inflorescência laxa, ereta, 25-50 flores; escapo 13-23 cm compr., $2 \mathrm{~mm}$ espessura, verde; brácteas do escapo 3-4, 5-30 × 2-3 mm, ovais, róseo-avermelhadas a verdes, ápice agudo; raque 3,5-9,5 cm compr., $2 \mathrm{~mm}$ espessura, verdes a 
róseo-avermelhadas. Brácteas das flores 3,4-4,2 × 1,3$2,1 \mathrm{~mm}$, lanceoladas, verdes a róseo-avermelhadas, ápice acuminado a agudo. Flor ereta, branca, sépala dorsal revoluta, 1,1-1,3 ×0,5-0,8 mm, oval, branca com mancha arroxeada no ápice, ápice agudo; sépalas laterais expandidas a revolutas, 1,5-1,6 $\times 0,9-1,5 \mathrm{~mm}$, triangulares, brancas com mancha arroxeada no ápice, ápice agudo; pétalas revolutas, 0,8-1,2 × 0,4-0,6 mm, lineares, brancas, ápice agudo a obtuso; labelo 1,42,2 × 1,0-1,7 mm, calceolado, membranáceo, branco, superfície interna pilosa; coluna $0,9 \mathrm{~mm}$ compr., glabra.

Distribuição geográfica e habitat (figura 5): Prescottia oligantha foi coletada em 22 municípios do Paraná, ocorrendo na Estepe Ombrófila, na Floresta Ombrófila Densa (Altomontana e Terras Baixas) e na Floresta Ombrófila Mista. Fora do Estado do Paraná, é encontrada nos Estados de Roraima, Bahia, Alagoas, Goiás, Mato Grosso do Sul, Minas Gerais, Espírito Santo, São Paulo, Rio de Janeiro, Santa Catarina, Rio Grande do Sul e no Distrito Federal (Barros et al. 2011).

Estado de conservação: Segundo os critérios da IUCN (2008), Prescottia oligantha não se enquadra como uma espécie ameaçada, devendo ser enquadrada na categoria pouco preocupante (LC).

Observações: O tamanho e a forma dessas plantas são extremamente variáveis, sem nenhum padrão evidente. Azevedo (2009) indica que Prescottia oligantha provavelmente pertença a um complexo de espécies. Floresce entre maio e novembro.

Material examinado: BRASIL: PARANÁ: Antonina, Reserva Natural Morro da Mina, Rio Xaxim, 16-XI-2003, M. Borgo 2649 (MBM); Balsa Nova, Serra São Luiz do Purunã, 7-X-1996, J. Cordeiro 1313 (MBM); Balsa Nova, BR 277, Serra São Luiz do Purunã, 28-X-1996, O.S. Ribas 1535 (MBM); Balsa Nova, Serra São Luiz do Purunã, 20-IX-2008, J.M. Silva 6986 (HUCP); Bocaiúva do Sul, Mandassaia, 11-X-1977, L.T. Dombrowski 7583 (MBM); Bocaiúva do Sul, Capivari, 16-X-1949, G. Hatschbach 1542 (MBM, SP); Bocaiúva do Sul, Salto, 12-XI-1959, G. Hatschbach 6475 (MBM); Castro, Fundão, 2-X-1964, G. Hatschbach 11648 (MBM); Curitiba, Jardim das Américas, 5-XI-1992, J. Cordeiro 893 (MBM); Curitiba, 20-IX-1915, P. Dusén 17167 (S); Curitiba, 7-XI-1948, G. Hatschbach 1074 (MBM, SP); Curitiba, Tarumã, 18-X-1971, G. Hatschbach 27659 (MBM); Curitiba, 19-X-1928, F.C. Hoehne s.n. (SP 23075); Guarapuava, Canta Galo, 26-IX-1968, G. Hatschbach 19869 (MBM); Guaratuba, Brejatuba, 8-VI1993, O. Guimarães 21039 (CTES, NY, SJRP, UPCB); Guaratuba, Brejatuba, 13-VIII-1950, G. Hatschbach 2118
(SP); Guaratuba, Brejatuba, 19-V-1991, J.M. Silva 1016 (BHCB, MBM); Guaratuba, 21-IX-1963, G. Hatschbach 10244 (MBM); Guaratuba, Serra de Araçatuba, Morro dos Perdidos, 5-III-1999, E.P. Santos et al. 761 (MBM, UPCB); Guaratuba, Balneário Nereidas, 11-VI-1993, J.M. Silva 1258 (MBM); Jaguariaíva, 30-X-1910, P. Dusén 10771 (S); Jaguariaíva, 27-IX-1911, P. Dusén 13048 (F, GH, NY, S); Lapa, Eng. Bley, 26-IX-1948, G. Hatschbach 1018 (MBM, SP); Lapa, Gruta do Monge, 3-X-1966, G. Hatschbach 14783 (MBM); Lapa, Rio Passa Dois, 30-IX-1969, G. Hatschbach 22252 (MBM); Lapa, Rio Passa Dois, 5-X-1958, G. Hatschbach 5052 (MBM); Lapa, Rio Iguaçu, 4-IX-2001, J.M. Silva 3434 (MBM); Laranjeiras do Sul, Rincão Grande, 12-X-1974, G. Hatschbach 35208 (MBM); Matinhos [Paranaguá], Caiobá, 2-VI-1961, G. Hatschbach 8150 (MBM); Morretes, margem da Estrada Graciosa, 22-IX-1946, G. Hatschbach 377 (MBM, RB); Morretes, 13-X-1976, Y.S. Kuniyoshi 4022 (MBM); Palmeira, Córrego da Anta, 30-IX-1982, G. Hatschbach 45498 (MBM); Paranaguá, Morro do Meio, Ilha do Mel, 29-V-1987, R.M. Britez 1535 (MBM); Paranaguá, Morro do Joaquim, Ilha do Mel, 12-IX-1987, R.M. Britez 1786 (MBM); Paranaguá, Morro do Joaquim, Ilha do Mel, 12-IX-1987, R.M. Britez 25726 (MBM); Paranaguá, Ilha do Mel, 16-VIII-1987, R.M. Britez 25726 (MBM); Paranaguá, Ilha do Mel, perto do cemitério e da usina elétrica, 5-VI-1996, A.A. Cocucci s.n. (MBM 226971); Paranaguá, Ilha do Mel, VII-1949, R. Hertel s.n. (FUEL 641); Paranaguá, Ilha do Mel, Praia do Bananal, 24-IX-2004, F.B. Matos et al. 54 (UPCB); Paranaguá, Ilha da Gamela, 19-VI-1992, A. Dunaiski Jr. 238 (BHCB, UPCB); Paranaguá, Alexandra, 11-X1975, A. Dziewa 76 (MBM); Paranaguá, Rio Perequê, 30-X-1966, G. Hatschbach 15201 (MBM); Paranaguá, Ipanema, 27-VIII-1969, G. Hatschbach 22114 (MBM, MO, NY, UPCB); Paranaguá, Rio Perequê, 31-V-1962, G. Hatschbach 9140 (MBM); Paranaguá, arredores, 12X-2003, O.S. Ribas 5190 (MBM); Paranaguá, Ilha das Cobras, 15-VI-1986, S.M. Silva 25024 (UEC); Ponta Grossa, Vila Velha, 07-X-1969, G. Hatschbach 22345 (MBM, UPCB); Porto de Cima, 19-X-1908, R. Lange 68915 (MBM); Porto de Cima, Serra do Mar, 1914, $P$. Dusén s.n. (GH 71598); Quatro Barras, Rio Taquari, 08X-1968, G. Hatschbach 19943 (MBM); Rio Branco do Sul, Serra do Votuvoru, 09-X-1975, G. Hatschbach 37314 (MBM, UEC); Sengés, Fda. Morungava, Rio do Funil, 09-IX-1959, G. Hatschbach 6283 (MBM); Tibagi, Alto do Amparo, 6-IX-1966, G. Hatschbach 14671 (MBM, US); Tunas do Paraná, 3-VIII-1966, J.C. Lindeman 1961 (MBM); Ventania, Rod. PR 153, Rio Laranjinha, 3-IX1998, G. Hatschbach 68305 (MBM). 
3.5. Prescottia stachyodes (Sw.) Lindl., Bot. Reg. 22: t. 1916: 1. 1836. $\equiv$ Cranichis stachyodes Sw., Prodr., 120. 1788. Tipo: JAMAICA (Blue Mountains), Swartz s.n. (lectótipo BM! selecionado por Azevedo \& van den Berg 2007a).

= Prescottia colorans Lindl., Bot. Reg. 22: t. 1916. 1836.

Tipo: BRASIL: Loddiges s.n. (holótipo K-L!).

Figura $4 \mathrm{H}-\mathrm{K}$

Erva terrestre. Folhas ca. 3, basais, pecioladas; pecíolo 9-16 cm compr., verde a róseo-avermelhado; lâmina 11-20,5 × 4,5-9,5 cm, membranácea a coriácea, elíptica a oval, ápice agudo, base atenuada a obtusa, verde escura a variegada, margem inteira a serrilhada. Inflorescência congesta a laxa, ereta, 25-60 flores; escapo 30-40 cm compr., 2-8 $\mathrm{mm}$ espessura, vermelho a verde; brácteas do escapo 6-8, 10-67 × 3-10 mm, oblongas, verdes a róseo-avermelhadas, ápice agudo; raque 4-20 cm compr., 2-3 $\mathrm{mm}$ espessura, verde a róseo-avermelhada. Brácteas das flores 4,36,5 × 1,3-3 mm, lanceoladas, róseo-avermelhadas a verdes, ápice agudo. Flor ereta, verde; sépala dorsal fortemente revoluta, 4-4,1 × 1,4-1,5 mm, membranácea, triangular, esbranquiçada a verde, ápice agudo; sépalas laterais fortemente revolutas, 4,6-5,7 × 1,2$1,6 \mathrm{~mm}$, membranáceas, triangulares a ovais, verdes a esbranquiçadas, ápice agudo; pétalas fortemente revolutas, 2-2,5 × 0,5-0,9 mm, membranáceas, lineares, verdes a esbranquiçadas, ápice agudo; labelo 3-3,8 × 1,7-3 mm, calceolado, membranáceo a submembranáceo, verde, superfície interna glabra; coluna 1,4-1,5 mm compr., glabra.

Distribuição geográfica e habitat(figura 5): Prescottia stachyodes foi coletada em 18 municípios do Paraná, ocorrendo na Estepe Ombrófila, na Floresta Estacional Semidecidual Subxérica, na Floresta Ombrófila Densa (Montana, Altomontana e Terras Baixas) e na Floresta Ombrófila Mista. Fora do Estado do Paraná, é encontrada nos Estados do Pará, Amazonas, Ceará, Pernambuco, Bahia, Alagoas, Minas Gerais, Espírito Santo, São Paulo, Rio de Janeiro, Santa Catarina, Rio Grande do Sul e no Distrito Federal (Barros et al. 2011).

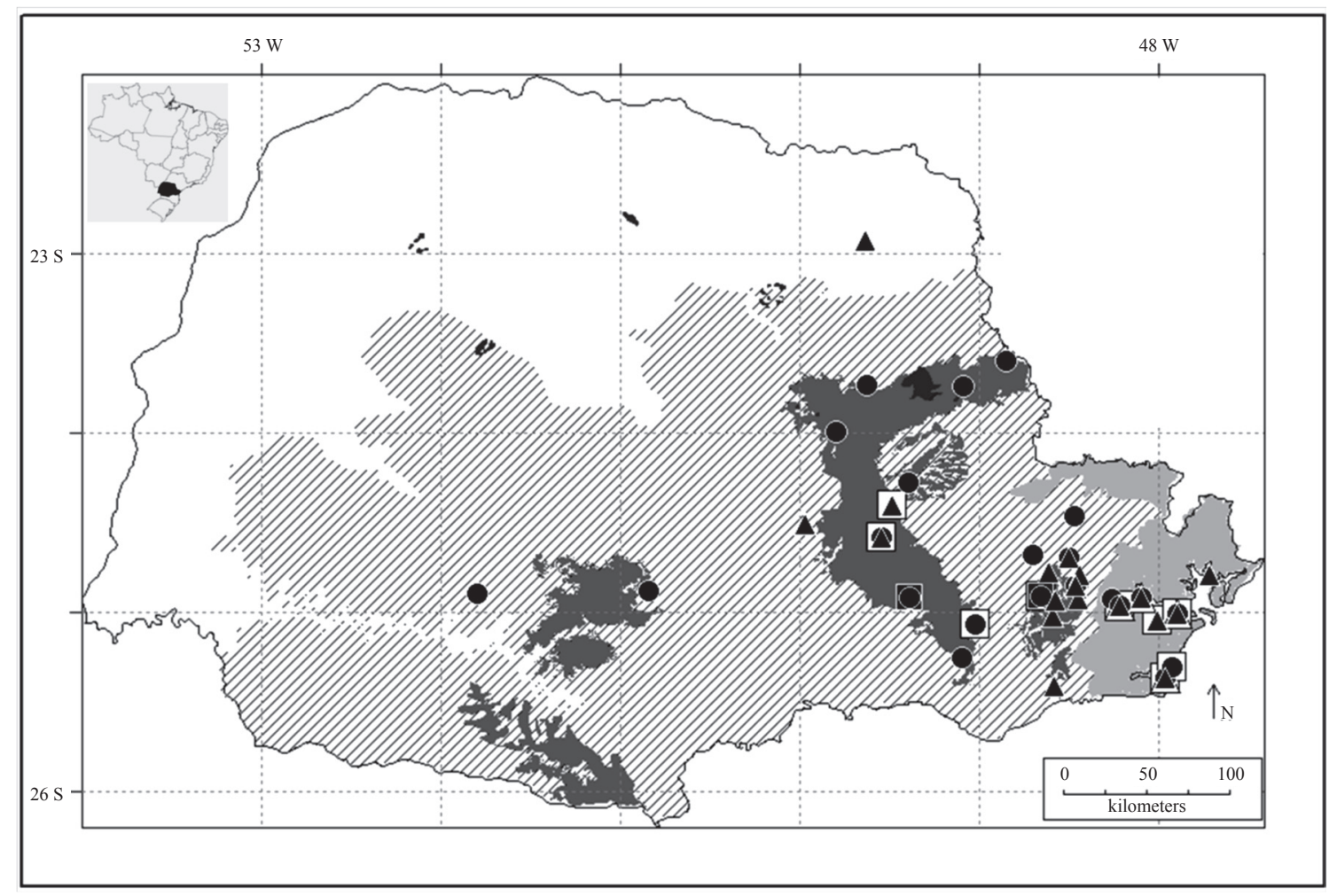

Figura 5.- Mapa da distribuição geográfica das espécies de Prescottia no Estado de Paraná ( $\square=$ estepe ombrófila; $\square=$ floresta estacional semidecidual subxérica; $\square=$ floresta ombrófila densa; $\mathbb{Z}=$ floresta ombrófila mista; $\square=$ savana estacional subxérica; $\boldsymbol{\Delta}=$ P. stachyodes $; \bullet=$ P. oligantha $\Delta=$ P. lancifolia $; \boldsymbol{\square}=$ P. montana $; \square=$ P. densiflora $)$.

Figure 5. Map the geographical distribution of Prescottia species in the Parana State ( $\square=$ ombrophilous steppe; $\square=$ subxeric semidecidous seasonal forest; $\square=$ dense ombrophilous forest; $\mathbb{E}=$ mixed ombrophilous forest; $\square=$ subxeric seasonal savanna; $\boldsymbol{\Delta}=$ P. stachyodes $; \boldsymbol{\bullet}=$ P. oligantha,$\Delta=$ P. lancifolia $; \boldsymbol{\square}=$ P. montana $; \square=$ P. densiflora $).$ 
Estado de conservação: Segundo os critérios da IUCN (2008) P. stachyodes não se enquadra como uma espécie ameaçada, devendo ser enquadrada na categoria pouco preocupante (LC).

Observações: As folhas de P. stachyodes são bem variáveis em seu formato, sua coloração e suas dimensões. Assim com Prescottia oligantha, provavelmente $P$. stachyodes também pertença a um complexo de espécies (Azevedo 2009). Estudos de populações ajudariam a esclarecer e elucidar a real circunscrição destas espécies. Floresce entre abril e outubro.

Material examinado: BRASIL: PARANÁ: 17-VI1910, F. Lange 8537 (MBM), 31-V-1915, F. Lange s.n. (MBM 214964), Rio Ipiranga, Serra do Mar, 24-VIII1909, R. Lange 3532 (MBM); Alexandra, 7-IX-1910, P. Dusén 10193 (F, S); Antonina, Serra Ibitiraquire, trilha para o pico Paraná, 18-X-2005, E. Barbosa 1120 (HUCP); Bocaiúva do Sul, Rio Capivari, 14/7/1986, J.M. Silva 131 (MBM); Campina Grande do Sul, Serra do Ibitiraquire, 16-V-2004, J.M. Silva 4065 (MBM); Carambeí, 17-VI-2008, M.E. Engels 9 (HUPG); Colombo, 1-VI-2005, R.S.F Possete \& S. Jesus 472 (MBM); Guaraqueçaba, Caminho ao Paruquara, 28X-1971, G. Hatschbach 27696 (MBM); Guaratuba, Serra de Araçatuba, Morro dos Perdidos, 5-V-2000, E.P. Santos et al. 893 (UPCB); Ipiranga, Roça Nova, Ypiranga, 17-VI-1909, P. Dusén 8537 (GH, NY, S); Jundiaí do Sul, Mata do Cruzeiro, 7-IX-2003, J. Carneiro 1500 (MBM); Morretes, Serra do Leão, 10X-1969, G. Hatschbach 22406 (MBM); Morretes, Serra do Morumbi, Pico Olimpo, 18-V-1982, G. Hatschbach 44941 (MBM, SP); Morretes, Serra da Prata, 29-IX1999, J.M. Silva 3070 (MBM, SPF); Morretes, Serra da Prata, encosta norte da Torre da Prata, 25-VIII2009, C.T. Blum 141 (UPCB); Morretes, Serra da Prata, encosta norte da Torre da Prata, 10-VI-2009, C.T. Blum 84 (UPCB); Paranaguá, Ilha das Cobras, 4V-1986, S.M. Silva 25016 (UEC); Paranaguá, Ilha do Mel, Morro Bento Alves, 21/4/1999, C. Kozera \& V.A. de O. Dittrich 1047 (UEC, UPCB); Paranaguá, Ilha do Mel, Morro Bento Alves, 9-X-1999, C. Kozera 1262 (UEC); Paranaguá, Ilha do Mel, Ponta Oeste, 14-VIII1987, R.M. Britez 1753 (MBM); Pinhais, 27-VI-2007, J.M. Silva 5854 (HUCP); Piraquara, Roça Nova, s.d., R. Lange 537 (MBM); Piraquara, Rio Taquary, 1-IX-1952, G. Hatschbach 2825 (MBM); Piraquara, Estr. PiraquaraBanhado, Serra da Boa Vista, 8-VI-1989, J.M. Silva 621 (MBM); Ponta Grossa, Vila Velha, 27-IX-2009, W.S. Mancinelli 958 (UPCB); Quatro Barras, Borda do Campo, 27-VI-1975, G. Hatschbach 37018 (MBM, US); São José dos Pinhais, Rio Pequeno, 3-VI-1970,
G. Hatschbach 24378 (MBM); São José dos Pinhais, Vassoroca, 16-V-1953, G. Hatschbach 3098 (MBM); São José dos Pinhais, Rincão, 06/1953, G. Hatschbach 3146 (MBM); Tijucas do Sul, Lagoinha, 29-VI-2002, D. Liebsch 454 (MBM).

Agradecimentos - Os autores agradecem os curadores dos herbários EFC, FUEL, HUCP, HUPG, MBM e UPCB pelo empréstimo dos materiais e Diana Carneiro pela confecção das ilustrações.

\section{Referências}

APG III. 2009. An update of the Angiosperm Phylogeny Group classification for the orders and families of flowering plants: APG III. Botanical Journal of the Linnean Society 161:105-121.

AZEVEDO, C.O. 2009. Filogenia e revisão taxonômica do gênero Prescottia Lindl. (Orchidaceae - Orchidoideae). Tese de Doutorado, Universidade Estadual de Feira de Santana, Feira de Santana.

AZEVEDO, C.O. \& VAN DEN BERG, C. 2007a. Lectotypifications in Prescottia (Orchidaceae Orchidoideae). Kew Bulletin 62:651-655.

AZEVEDO, C.O. \& VAN DEN BERG, C. 2007b. A Família Orchidaceae no Parque Municipal de Mucugê, Bahia, Brasil. Hoehnea 34:1-47.

BARROS, F. DE, VINHOS, F., RODRIGUES, V.T., BARBERENA, F.F.V.A. \& FRAGA, C.N. 2010. Orchidaceae. In Lista de Espécies da Flora do Brasil. Jardim Botânico do Rio de Janeiro. http://floradobrasil. jbrj.gov.br/2010/FB000179 (acesso em 12/07/2010).

BRUMMITT, R.K. \& POWELL, C.E. 1992. Authors of plants names. Royal Botanic Gardens, Kew.

COGNIAUX, A. 1983-1986. Orchidaceae. In Flora Brasiliensis (C.F.P. Martius, A.G. Eichler \& I. Urban, eds.). F. Fleischer, Lipsiae, v.3. pars 4. p.1-672.

DRESSLER, L.R. 1993. Phylogeny and classification of the orchid family. Dioscorides Press, Portland.

GONÇALVES, E.G. \& LORENZI, H. 2007. Morfologia vegetal: organografia e dicionário ilustrado de morfologia das plantas vasculares. Instituto Plantarum de Estudos da Flora, São Paulo.

GOVAERTS, R. 2010. The Board of Trustees of the Royal Botanic Gardens, Kew. http://apps.kew.org/wcsp/home. do (em: 24/02/2010).

HARRIS, J.G. \& HARRIS, M.W. 1994. Plant identification terminology: an illustrated glossary. Spring Lake Publishing, Utah.

HIJMANS, R.J., GUARINO, L., BUSSINK, C., MATHUR, P., CRUZ, M., BARRENTES, I. \& ROJAS, E. 2005. DIVA-GIS: A geographic information system for the analysis of species distribution data. Versão 5.2. http:// www.diva-gis.org (acesso em 24/02/2010). 
HOEHNE, F.C. 1945. Orchidaceas. In Flora brasílica (F.C. Hoehne, ed.). Secretaria da Agricultura, Indústria e Comércio de São Paulo, São Paulo, v.12, parte 2, p.1-389.

HOLMGREN, P.K., HOLMGREN, N.H. \& BARNETT, L.C. 1990. Index Herbariorum. Part I: The Herbaria of the World. New York Botanical Garden, New York.

IUCN STANDARDS AND PETITIONS WORKING GROUP. 2008. Guidelines for Using the IUCN Red List Categories and Criteria. Versão 7.0. http://intranet.iucn. org/webfiles/doc/SSC/RedList/RedListGuidelines.pdf (acesso em 24/02/2010).

MAACK, R. 1968. Geografia física do Paraná. BADEPUniversidade Federal do Paraná, Curitiba.

PABST, G.F.J. \& DUNGS, F. 1975. Orchidaceae Brasilienses. v. 1. Kurt Schmersow, Hildesheim.
PRIDGEON, A.M., CRIBB, P.J., CHASE, M.W. \& RASMUSSEN, F. 2003. Genera Orchidacearum. v.3: Orchidoideae. pt. 2: Vanilloideae. Oxford University Press, Oxford.

RAVEN, H.P., EVERT, R.F. \& EICHHORN, S.E. 2007. Biologia Vegetal. $7^{\text {ed }}$. Editora Guanabara Koogan, Rio de Janeiro.

SALAZAR, G.A., CHASE, M.W., SOTO ARENAS, M.A. \& INGROUILLE, M. 2003. Phylogenetics of Cranichideae with emphasis on Spiranthinae (Orchidaceae, Orchidoideae): evidence from plastid and nuclear DNA sequences. American Journal of Botany 90:777-795.

STERN, W.T. 2004. Botanical Latin. Timber Press, Portland.

VELOSO, H.P., RANGEL FILHO, A.L.R. \& LIMA, J.C.A. 1991. Classificação da vegetação brasileira adaptada a um sistema universal. Instituto Brasileiro de Geografia e Estatística/Projeto RadamBrasil, Rio de Janeiro. 